\title{
Complex Detection Between Transcription Regulator and Promoter DNA by UV Spectroscopic Method
}

\author{
Kyungmin Lee and Jongback Gang ${ }^{\dagger}$
}

\begin{abstract}
UV spectrophotometer was used to detect protein-DNA complex from DNA melting profile under constant temperature increase. Melting temperature (Tm) was $43^{\circ} \mathrm{C}$ in copA duplex DNA alone. In the presence of Proteus mirabilis transcription regulator protein (PMTR) protein at 0.2 and $0.4 \mu \mathrm{M}$, Tm's were $45 \pm 0.5$ and $47.6 \pm 0.6^{\circ} \mathrm{C}$, respectively. According to fluorescence polarization and gel shift assay. PMTR:copA complex was detected by the retarded migration on gel and the dissociation constant $\left(K_{d}\right)$ was $(9.2 \pm 2.8) \times 10^{-9} \mathrm{M}$.
\end{abstract}

Key words: Spectroscopic Method, Melting Temperature, Metalloregulator, Transcription Regulator

\section{Introduction}

DNA-protein interactions play a central role in a wide range of cellular processes including transcription regulation, DNA replication, genetic recombination, DNA repair, and the restriction and modification of $\mathrm{DNA}^{[1]}$. Proteins active in these processes recognize specific binding sequences with an increased affinity over nonspecific interactions with DNA. DNA recognition by protein is a specific hydrogen bonding contacts to the DNA bases and/or interactions with the sugar-phosphate backbone ${ }^{[1]}$. DNA-protein complex is an important biological evidence to elucidate the role of any particular protein in cellular processes. There are many biochemical methods known for the detections of protein-DNA interactions. Examples are fluorescence spectroscopy ${ }^{[2]}$, circular dichroism spectroscopy, gel mobility assay $^{[3]}$, DNase I footprinting ${ }^{[4]}$, DNA-protein photocrosslinking $^{[5]}$, and south-western blotting ${ }^{[6]}$.

Based on the dependence of optical density of DNA on temperature, DNA melting temperatures (Tm) was determined for the complex detection between protein and duplex DNA through the relative stability of DNA. In this study, short duplex DNA was used to obtain melting profiles with UV spectrophotometer. For the

Department of Chemistry, Gachon University, Sungnam 461-701, Korea

${ }^{\dagger}$ Corresponding author : jbgang@gachon.ac.kr

(Received : August 29, 2012, Revised : September 20, 2012,

Accepted : September 25, 2012) measurement of the specific binding of transcription regulator to DNA, proteus mirabilis transcription regulator (PMTR) protein, a newly discovered metalloregulatory protein was used in this study ${ }^{[7]}$.

Iron, zinc, copper, manganese, cobalt, etc. are essential metal ions used in the redox processes, osmotic pressure control, and also enzyme components ${ }^{[8]}$. Metalloregulatory protein functions to maintain the appropriate concentration of metals ions within cells, because high metal concentration is caused to DNA and membrane damage and loss of enzyme function. At high metal circumstance, metalloregulatory proteins need to activate the specific genes corresponding to the metal homeostasis system (intra- and extracellular sequestration, efflux pumps, enzymatic detoxification, and reduction $)^{[9]}$.

From the information of amino acids sequence alignment between PMTR and copper regulatory protein of Escherichia coli CueR (copper metalloregulatory protein), PMTR protein retains two cysteins of Cys112 and Cys120 in consistent with those of CueR protein in metal binding site ${ }^{[10]}$. Thus, this study use Escherichia coli copA (copper-translocating ATPase gene) promoter to detect complex between protein and DNA promoter by UV spectroscopic method.

In addition, Fluorescence polarization measurement and gel shift assay also conducted in the same condition for the verification of the results by UV spectroscopic measurement. 


\section{Experimental Section}

CopA oligodeoxynucleotides(Sigma-Aldrich Kore) sequences are 5'-cttgaccttcccttgctggaaggtttaacctt-3' and 5'-aaggttaaaccttccagcaaggggaaggtcaag-3'. cop $A$ oligodeoxynucleotides corresponds to the promoter/operator region of copA gene of Escherichia. coli ${ }^{[11]}$.

\subsection{Protein Purification}

The gene encoding $p m t R$ was PCR-amplified from a plasmid containing a fragment of the proteus mirabilis genome, designated PROT1 ${ }^{[7]}$. The amplified DNA fragment was subcloned into $\mathrm{pET} 15 \mathrm{~b}$ expression vector (Novagen) and its recombinant vector in BL21 (DE3) produces PMTR protein with (His) $)_{6}$ tag at $\mathrm{N}$-terminal. PMTR protein in BL21 pETpmtR was induced in the presence of $0.5 \mathrm{mM}$ isopropyl- $\beta$-thiogalactopyranoside (IPTG) at $25^{\circ} \mathrm{C}$. Protein has been purified with Ni-NTA agarose column by imidazole gradient elution. Protein solution was concentrated with amicon ultrafiltration unit under $\mathrm{N}_{2}$ atmosphere.

\subsection{Optical Density Measurement}

Template and non-template strands of copA oligodeoxynucleotides were annealed to form duplex DNA by mixing equimolar amounts of each strand in $10 \mathrm{mM}$ sodium cacodylate, $\mathrm{pH} 6.5$, heating to $80^{\circ} \mathrm{C}$ for $10 \mathrm{~min}$ utes, and allowing the solution to cool slowly down to room temperature.

Absorbance changes were measured with UV spectrophotometer (UV 2401PC, Shimadzu) in $20 \mathrm{mM}$ Tris (pH 7.6), $50 \mathrm{mM} \mathrm{NaCl}$, and $1 \mu \mathrm{g} / \mathrm{mL}$ poly $\mathrm{d}(\mathrm{I} \cdot \mathrm{C})$ in the presence of PMTR and $0.4 \mu \mathrm{M} \operatorname{cop} A$ duplex DNA. Temperature was increased at the rate of $1{ }^{\circ} \mathrm{C} / \mathrm{min}$ with water circulation system connected to the sample holder. The measured data were plotted and analyzed with Origin 6.0 (Microcal Software, Inc).

\subsection{Fluorescence Polarization}

To measure interactions between PMTR protein and copA DNA, Fluorescence polarization (FP) was measured in binding buffer (20 mM Tris ( $\mathrm{pH} 7.6), 50 \mathrm{mM}$ $\mathrm{NaCl}$, and $1 \mu \mathrm{g} / \mathrm{mL}$ poly $\mathrm{d}(\mathrm{I} \cdot \mathrm{C})$ ) containing $1 \mathrm{nM}$ of 5 fluorescein labeled copA duplex in the presence of various concentration of PMTR protein with Victor 3 multilabel reader whose excitation and emission wavelengths were 485 and $535 \mathrm{~nm}$, respectively (PerkinElmer, Agri- cultural and Biotechnology Research Center, Seoul).

\subsection{Gel Shift Assay}

Reaction was conducted with $0.1 \mu \mathrm{M}$ of 5'-fluorescein-labeled copA promoter DNA for $20 \mathrm{~min}$ at room temperature temperature $\left(\sim 15^{\circ} \mathrm{C}\right)$. Binding reaction was included with $0.1 \mu \mathrm{M}$ cop $A$ DNA, $10 \mu \mathrm{g} / \mathrm{mL}$ poly $\mathrm{d}(\mathrm{I} \cdot \mathrm{C})$, and several different concentrations of PMTR. Reactions were electrophoresized in TAE buffer (Tris-Acetate EDTA) on $12 \%$ native polyacrylamide gel and visualized with Kodak image scanner at excitation of $470 \mathrm{~nm}$ and emission of $535 \mathrm{~nm}$.

\section{Results and Discussion}

PMTR protein was purified with Ni-NTA agarose column by imidazole concentration gradient as shown in Fig. 1. PMTR protein showed $95 \%$ of purity on $10 \%$ SDS polyacrylamide gel. Due to the low solubility of PMTR protein, protein was induced with $0.5 \mathrm{mM} \mathrm{IPTG}$ at low temperature and carefully concentrated to $1 / 4 \mathrm{~V}$ with the ultrafiltration device under $\mathrm{N}_{2}$ atmosphere.

Fig. 2A, 3A, and 4A show DNA melting profiles in the presence of $0,0.2$, and $0.4 \mu \mathrm{M}$ PMTR, respectively. Melting curves were fitted with non-linear regression of Origin 6.0 program. Tm of DNA is the temperature corresponding to the peak of first derivatives of melting curves $(\mathrm{dA} / \mathrm{dT})$. As shown in Fig. $2 \mathrm{~B}$, Tm was $43^{\circ} \mathrm{C}$ with no PMTR protein. In addition, Tm's were gradually increased to $45 \pm 0.5$ (Fig. 3B) and $47.6 \pm 0.6$ (Fig.

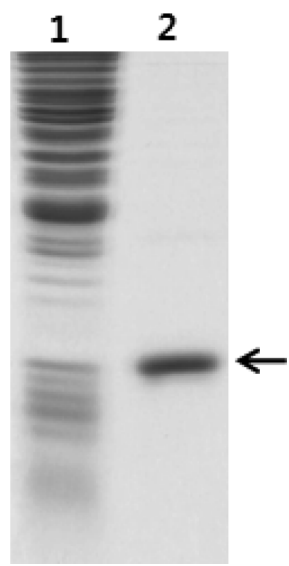

Fig. 1. SDS-PAGE. Lane 1 is protein profile of IPTGinduced BL21pETpmtr. Lane 2 is purified PMTR protein. Arrow indicates PMTR protein. 


\section{$-35$ TCTTGACCTTCCCCTIGCTGGAAGGTTAACCTTT AGAACTGGAAGGGGAACGACCTTCCAAATTGGAAA}

Fig. 2. Promoter sequence of $\operatorname{cop} A$ gene ${ }^{[7]}$. The base sequence in a box was copA duplex DNA used for this experiment. -35 and -10 regions are bolded. Arrows indicate the inverted repeat sequences of $E$. coli copA.

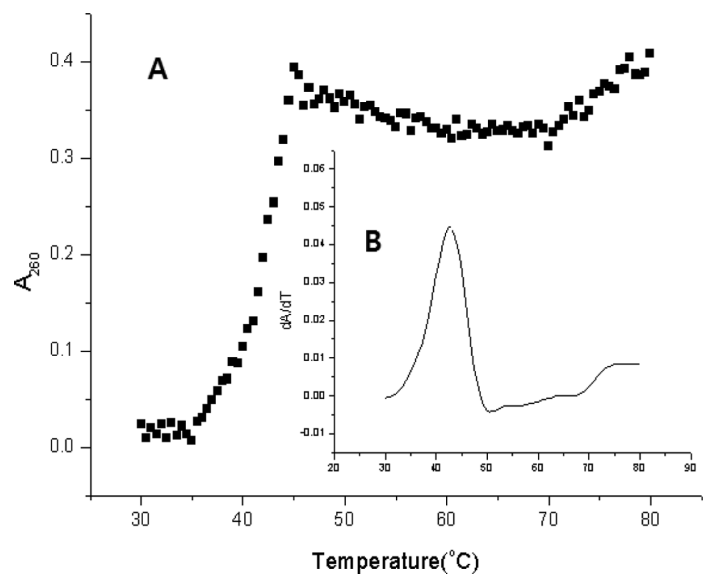

Fig. 3. Melting profile of duplex DNA without PMTR. Absorbances are plotted against temperature(A). Temperature is continuously raised at $1^{\circ} \mathrm{C} / \mathrm{min}$. Duplex DNA was used at $0.4 \mu \mathrm{M}$. The small graph(B) inside melting curve shows differential $\operatorname{plot}(\mathrm{dA} / \mathrm{dT})$ against temperature with Origin 6.0 program.

4B) in the presence of 0.2 and $0.4 \mu \mathrm{M}$ PMTR, respectively. It is direct evidence that PMTR protein binds specifically to copA duplex DNA. PMTR increased stability of DNA by covering (wrapping) double helix through specific interactions between PMTR and duplex DNA.

Binding of the regulatory protein ArgR which autoregulates its own $\arg R$ gene in T. neapolitana to an operator increased the melting temperature of DNA to approximately $15^{\circ} \mathrm{C}^{[12]}$.

It is possible that absorbance measurement was also affected by PMTR protein itself.

To verify the contribution of protein to optical density, absorbance of PMTR was monitored under same condition as melting experiment. Absorbance of protein was not dramatically increased until the melting temperature at constant increase of temperature (unpublished data). As shown in the early stage of melting

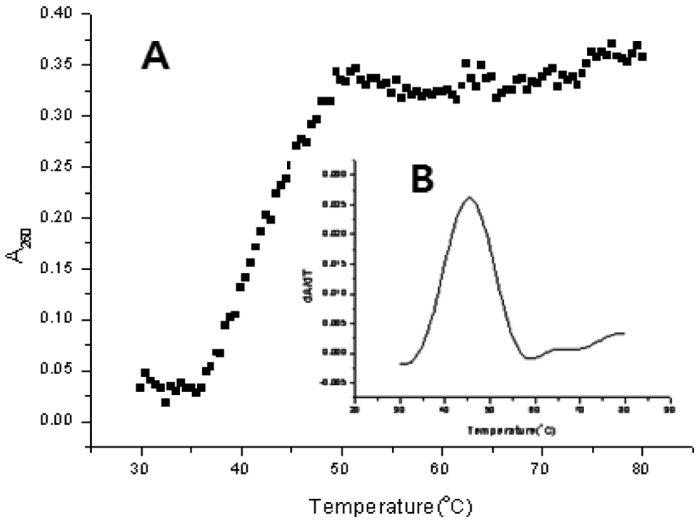

Fig. 4. Melting profile of duplex DNA with $0.2 \mu \mathrm{M}$ PMTR. Tm was determined by non-linear regression analysis with Origin 6.0 program.

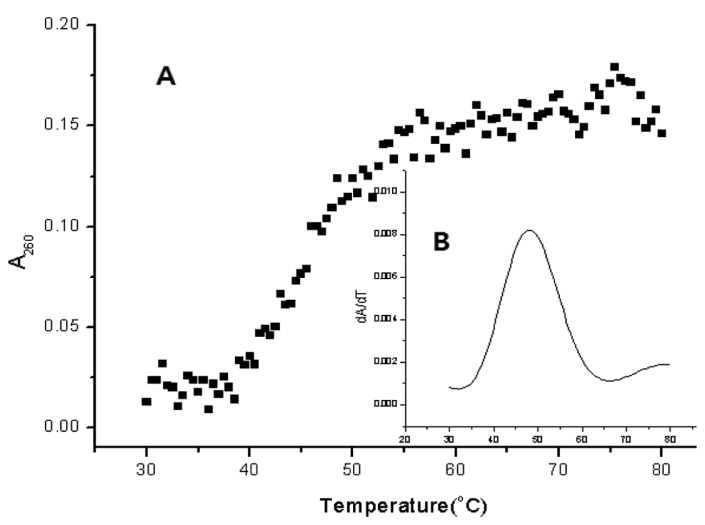

Fig. 5. Melting profile of duplex DNA with $0.4 \mu \mathrm{M}$ PMTR. Tm was determined by non-linear regression analysis with Origin 6.0 program.

profile, PMTR protein did not contribute strongly to absorbance measurement. In addition, measurement is also influenced by thermal stability of protein. If it is not denatured prior to the melting temperature of DNA alone, Tm value will be increased. Thus, the increased Tm value is the evidence to verify complex formation between protein and promoter DNA.

To rationalize UV spectroscopic measurement for the detection of DNA:protein complex, fluorescence polarization (FP) was measured with $1 \mathrm{nM}$ of 5 '-fluorescein labeled copA duplex in the presence of various concentration of PMTR protein with Victor 3 multilabel reader whose excitation and emission wavelengths were 485 and $535 \mathrm{~nm}$ (PerkinElmer, Agricultural and Biotechnological Research Center, Seoul National University). As 


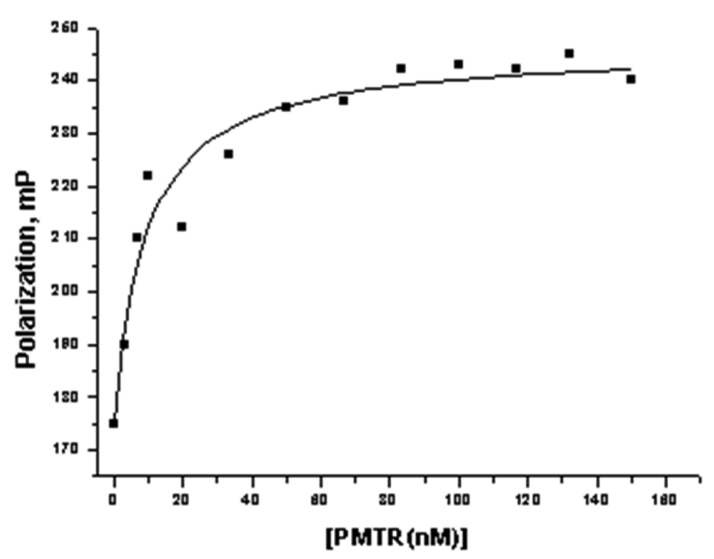

Fig. 6. Fluorescence polarization at given concentrations of PMTR. $1 \mathrm{nM}$ of 5'-fluorescein-labeled copA duplex DNA was used for this measurement. Excitation and emission wavelengths were 485 and $535 \mathrm{~nm}$, respectively. Dissociation constant $\left(K_{d}\right)$ was determined by fitting of plot.

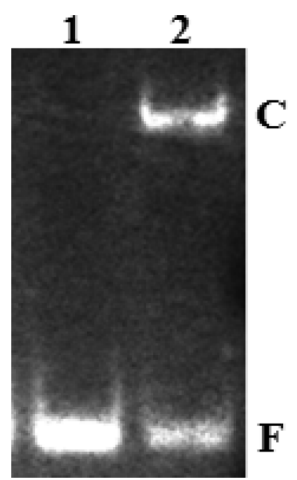

Fig. 7. Gel shift assay with 5-fluorescein labeled copA DNA. Lane 1 contains $0.1 \mu \mathrm{M}$ copA DNA. Lane 2 contain $0.6 \mu \mathrm{M}$ PMTR with $0.1 \mu \mathrm{M}$ copA DNA. C represent PMTR:copA DNA complex. F indicates free copA DNA.

shown in Fig. 6, typical binding isotherm was plotted by polarizations $(\mathrm{mP})$ against PMTR concentration. Dissociation constant $\left(K_{d}\right)$ was determined using the following equation ${ }^{[13]}$ :

$$
P=\frac{\left(P_{\text {bound }}-P_{\text {free }}\right)[P M T R]}{K_{d}+[P M T R]}+P_{\text {free }}
$$

where $P$ is the polarization measured at any PMTR concentration [PMTR], $P_{\text {bound }}$ is the polarization of DNA bound maximally by protein, and $P_{\text {free }}$ is the polarization of free DNA.

Non-linear regression analysis determined that $K_{d}$ was $(9.2 \pm 2.8) \times 10^{-9} \mathrm{M}$. It indicates that PMTR protein binds to fluorescein-labeled $\operatorname{cop} A$ promoter DNA with high affinity.

To visualize PMTR protein:DNA complex, gel shift assay (shown in Fig. 7) was conducted with 5'-fluorescein labeled copA promoter. Binding reaction was done at room temperature with $0.1 \mu \mathrm{M} \operatorname{cop} A$ DNA, $10 \mu \mathrm{g}$ / $\mathrm{mL}$ poly $\mathrm{d}(\mathrm{I} \cdot \mathrm{C})$, and several different concentrations of PMTR. PMTR:copA DNA complex was detected with Kodak image scanner at excitation of $470 \mathrm{~nm}$ and emission of $535 \mathrm{~nm}$ wavelengths.

CopA DNA formed complex with PMTR protein which resulted in the retarded gel migration relative to free DNA. It indicates that copA promoter is recognized and specifically bound by PMTR protein with the high binding affinity. It is likely that PMTR protein recognizes the inverted repeat sequence of -ACCTTCC- like CueR protein.

\section{Conclusion}

In summary, UV spectrophotometer can be used to detect protein-DNA complex if the following conditions are met: 1) use of short length of DNA fragment and 2) stable protein(protein is thermally more stable than DNA fragment). According to fluorescence polarization and gel shift assay, PMTR:copA complex was detected by the retarded migration on gel and $K_{d}$ of $9.2 \pm 2.8 \times$ $10^{-9} \mathrm{M}$.

\section{Acknowledgements}

We wish to thank Dr Richard G. Brennan (Department of Biochemistry and Molecular Biology, University of Texas, MD Anderson Cancer Center at Houston) and Dr S. Lutsenko (Department of Biochemistry and Molecular Biology, Oregon Health and Sciences University, Portland) for the gift of $p m t R$ cloned vector and PROT $_{1}$ plasmid.

\section{References}

[1] M. J. Guille and G. G. Kneale, "Methods for the analysis of DNA-protein interaction", Mol. Biotechnol., Vol. 8. pp. 35-52, 1997.

[2] M. L. Carpenter and G. G. Kneale, "Circular dichro- 
ism and fluorescence analysis of the interaction of Pfl gene 5 protein with poly(dT)", J. Mol. Biol., Vol. 217, pp. 681-689, 1991.

[3] M. G. Fried and D. M. Crothers, "Equilibria and kinetics of lac repressor-operator interactions by polyacrylamide gel electrophoresis", Nucleic Acids Res., Vol. 9, pp. 6505-6525. 1981.

[4] A. Schmitz and D. J. Galas, "DNase I footprinting: a simple method for the detection of protein-DNA binding specificity", Nucleic Acids Res., Vol. 5, pp. 3157-3170, 1978.

[5] J. Welsh and C. R. Cantor. "Protein-DNA crosslinking", Trends Biochem. Sci., Vol. 9, pp. 505-507, 1984.

[6] H. Singh, J. H. LeBowitz, A. S. Baldwin, and P. A. Sharp, "Molecular cloning of an enhancer binding protein: isolation by screening an expression library with recognition site DNA" Cell, Vol. 52, pp. 415423, 1988.

[7] M. Noll, K. Petrukhin, and S. Lutchenko, "Identification of a novel transcription regulator from Proteus mirabilis, PMTR, revealed a possible role of YJAI protein in balancing zinc in E. coli", J. Biol. Chem., Vol. 273, pp. 21393-21401, 1998.

[8] E. A. Permina, A. E. Kazakov, O. V. Kalininia, and M. S. Gelfand, "Comparative genomics of regula- tion of heavy metal resistance in Eubacteria", BMC Microbiol., Vol. 6. pp. 1-11, 2006.

[9] D. H. Nies, "Microbial heavy-metal resistance", Appl. Microbiol. Biotechnol., Vol. 51. pp. 730-750, 1999.

[10] A. Changela, K. Chen, Y. Xue, J. Holschen, C. E. Outten, T. V. O'Halloran, and A. Mondragon, "Molecular basis of metal-ion selectivity and zeptomolar sensitivity by CueR' Science, Vol. 301. pp. 1383-1387, 2003.

[11] F. W. Outten, C. E. Outten, J. Hale, and T. V. O'Halloran, "Transcription activation of an Escherichia coli copper efflux regulon by the chromosomal MerR homologue, CueR", J. Biol. Chem., Vol. 275, pp. 31024-31029, 2000.

[12] D. Dimova, P. Weigel, M. Takahashi, F. Marc, G. D. Van Duyne, and V. Sakanyan, "Thermostability, oligomerizatin and DNA-binding properties of the regulatory protein ArgR from the hyperthermophilic bacterium thermotoga neapolitana", Mol. Gen. Genet., Vol. 263, pp. 119-130. 2000.

[13] J. R. Lunblad, M. Laurance, and R. H. Goodman, "Fluorescence polarization analysis of protein-DNA and protein-protein interaction", Mol. Endocrinol. Vol. 10, pp. 607-612, 1996. 